\title{
COMPORTAMENTO PÓS-COLHEITA DE CAQUIS cv. Fuyu, ATRAVÉS DA ATMOSFERA MODIFICADA PASSIVA E DA ADSORÇÃO DE ETILENO, ARMAZENADOS SOB REFRIGERAÇÃ̃O ${ }^{1}$
}

\author{
LEANDROCAMARGO NEVES ${ }^{2} ;$ RONALDO MORENO BENEDETTE $^{4}$; VANUZAXAVIER DA SILVA ${ }^{4}$; \\ LUCIANO LUCHETTA $^{3}$; MARCIO ROGGIAZANUZZO ${ }^{3}$; CESAR VALMOR ROMBALDI $^{5}$
}

\begin{abstract}
RESUMO - O trabalho foi realizado no Departamento de Ciência e Tecnologia Agroindustrial, da UFPel/Pelotas, com o objetivo de avaliar a utilização de embalagens de polietileno de baixa densidade (PEBD) e do adsorvedor de etileno em caquis cv. Fuyu. Na safra de 2000-2001, os frutos foram armazenados a granel, em embalagens de PEBD de 0,022 mm contendo doze e 40 frutos e em embalagens de PEBD de $0,033 \mathrm{~mm}$ contendo doze frutos, sendo que apenas metade das embalagens possuía o sachê adsorvedor de etileno. De acordo com as variáveis analisadas (distúrbios fisiológicos, concentração/produção de $\mathrm{CO}_{2}$ e etileno), os frutos acondicionados nas embalagens de 0,022 mm contendo doze frutos, com e sem o adsorvedor, apresentavam-se em estádio menos avançado de amadurecimento e com qualidade superior aos demais tratamentos. Já na safra de 2001 - 2002, sob os mesmos parâmetros avaliados no ano anterior, foram testados o armazenamento a granel e o armazenamento em embalagens de PEBD de $0,022 \mathrm{~mm}$, contendo doze, dezoito e 24 frutos, também com e sem a utilização de sachê adsorvedor de etileno. Após 90 dias de armazenamento refrigerado (AR), mais os cinco dias de simulação de comercialização, os frutos acondicionados nas embalagens de $0,022 \mathrm{~mm}$, contendo doze e dezoito frutos, independentemente do sistema de adsorção de etileno, apresentaram os melhores resultados em todas as variáveis testadas.
\end{abstract}

Termos para indexação: Diospyrus kaki L., PEBD, injúria pelo frio, qualidade.

\section{POSTHARVEST BEHAVIOR OF PERSIMMONS cv. Fuyu THROUGH PASSIVE MODIFIED ATMOSPHERE AND ETHYLENE ADSORPTION STORED UNDER REFRIGERATION}

\begin{abstract}
The experiments were carried out at the Science and Technology Agroindustry Department of UFPel/Pelotas, with the objective to improve the use of polyethylene packing of low density (PPLD) and the adsorption of ethylene, in Fuyu persimmons. During the season of 00/01, the fruits were stored without packing, in 0,022 mm PPLD packing with capacity for 12 or 40 fruits and in 0,033 mm PPLD packing with capacity for 12 units. Except for the control treatment, all the other treatments were combined with (50\%) or without (50\%) ethylene absorption. According to the analyzed variables (physiological disorders, $\mathrm{CO}_{2}$ and ethylene concentration/production), indicated that the persimmons stored in $0,022 \mathrm{~mm}$ bags containing 12 fruits, with or without the ethylene absorption, were found in a condition of less advanced ripening and with better quality compared to the other treatments. In the season $01 / 02$, under the same parameters tested in the last season, the storage without packing and the storage in 0,022 mm PPLD with 12, 18 and 24 fruits, with and without the use of ethylene absorption were tested. After 90 days of refrigerated storage (R.S.), plus 5 days in simulated trading condition $\left(22 \pm 3{ }^{\circ} \mathrm{C}\right.$ and $75 \pm 5 \%$ of RH), the fruits kept in the packing of $0,022 \mathrm{~mm}$ with 12 and 18 fruits, with or without the ethylene absorption produced the best results in all tested variables.
\end{abstract}

Index terms: Diospyrus kaki L., PPLD, chilling injury, quality.

\section{INTRODUÇ̃̃o}

O caqui possui elevada importância econômica no Brasil, estando estabelecido nas regiões Sul e Sudeste, onde ocorrem condições climáticas favoráveis ao seu desenvolvimento (Brackmann \& Saquet, 1995). O Estado de São Paulo é o maior produtor, com 2850 ha plantados, seguido pelo Rio Grande do Sul, com 700 ha e Rio de Janeiro com 500 ha cultivados (Ceagesp, 1997).

Dentre as cultivares existentes, ocorre um especial interesse por aquelas que possuem os frutos não-taninosos. A cultivar Fuyu caracteriza-se pela presença de frutos grandes - 180 a $260 \mathrm{~g}$, não adstringentes, coloração variando de amarelo-alaranjada a alaranjado-avermelhada, desprovidos de semente, sendo citada como a principal cultivar em exploração atualmente (Ben-Arie \& Zutkhi, 1992).

Segundo MacRae (1987), o caqui Fuyu possui excelente potencialidade para a exportação. Países como Estados Unidos, Israel e Japão estão entre os maiores exportadores, devido principalmente à capacidade que seus frutos apresentam no $\mathrm{AR}$, no controle da injúria pelo frio, como, por exemplo: escurecimento epidérmico e degenerescência de polpa (Prusky, 2001; Ferri, 2000; Ben-Arie, 1995), elevada perda de firmeza de polpa e o desenvolvimento de sabor e odor não característicos (off flavors).

Segundo Mosca et al. (1999), o acondicionamento de frutos em filmes plásticos diminui a respiração, transpiração e outras reações metabólicas que ocorrem no produto, através da manutenção de uma atmosfera interna adequada. Entretanto, faz-se necessário o estudo das condições ideais, como a densidade do filme, o número de frutos por embalagem e a temperatura de frigoarmazenamento, evitando assim alterações indevidas na atmosfera gasosa da embalagem, os quais podem provocar desde alterações na cor e firmeza dos frutos até o desenvolvimento de offflavors.

Nas espécies produtoras de frutos climatéricos, o etileno atua como agente indutor e regulador da velocidade da maturação/senescência. Por isto, a adoção de medidas que reduzam a produção e/ou a ação deste fitoregulador, tais como o uso de adsorvedores de etileno, podem retardar a velocidade de maturação/ senescência, aumentando, por conseguinte, sua conservabilidade (Chaves et al., 1997).

Neste sentido, avaliou-se o comportamento pós-colheita de caquis da cv. Fuyu, em duas safras consecutivas, através da

\footnotetext{
1 (Trabalho 40-2006). Recebido: 04-04-2006. Aceito para publicação: 25-08-2006.

${ }^{2}$ UFRR - Prof. Depto. de Fitotecnia - Centro de Ciências Agrárias, km 12 - BR 174 s/nº, CEP 69301-970, Boa Vista - RR. E-mail: rapelbtu@ @otmail.com

${ }^{3}$ UFRR - Pós-Graduando em Ciência e Tecnologia Agroindustrial - Faculdade de Agronomia Eliseu Maciel, Cx. P. 354, CEP 96010-900, Pelotas - RS. E-mail: lucianolucchetta@yahoo.com.br; zanuzo@yahoo.com.br

${ }^{4}$ UFRR - Prof. Depto. de Fitotecnia - Centro de Ciências Agrárias, km 12 - BR 174 s/nº CEP 69301-970, Boa Vista - RR. E-mail: rmbenedette@ hotmail.com; vxsilva@ hotmail.com

${ }^{5}$ UNESP/FCA - Prof. Depto. de Ciência e Tecnologia Industrial - Faculdade de Agronomia Eliseu Maciel, Cx. P. 354, CEP 96010-900, Pelotas / RS. Email: cesarvrf@ufpel.tche.br
} 
utilização de embalagens de PEBD, de diferentes espessuras e da utilização do sachê adsorvedor de etileno.

\section{MATERIAIS E MÉTODOS}

Os frutos de caqui da cv. Fuyu, da SAFRA de 20002001, foram colhidos fisiologicamente maturos, apresentando coloração amarelo-alaranjada, teor médio de sólidos solúveis totais de $14,7^{\circ}$ Brix, firmeza de polpa média de $82 \mathrm{~N}$ e peso médio dos frutos de $280 \mathrm{~g}$. Após a colheita, os frutos foram pré-resfriados até que a temperatura da polpa dos frutos atingisse $2 \pm 1{ }^{\circ} \mathrm{C}$. Em seguida, os frutos foram embalados, testando-se o efeito da espessura da embalagem de PEBD e do sachê de adsorção de etileno. As embalagens com capacidade para 40 frutos apresentavam dimensões de $0,95 \times 0,42 \mathrm{~m}$, enquanto as embalagens com capacidade para 12 frutos apresentavam dimensões de 0,40 x 0,42 m. Para a adsorção de etileno, utilizou-se 1 sachê/embalagem, marca comercial Longfresh $®$, peso unitário de $9 \mathrm{~g}$, contendo silicato de alumínio e permanganato de potássio. Os tratamentos foram assim distribuídos: T1 - frutos a granel em caixas com capacidade unitária de $20 \mathrm{~kg}$ (controle); T2 40 frutos em embalagens de PEBD de $0,022 \mathrm{~mm}\left(\mathrm{~d}=0,932 \mathrm{~g} \cdot \mathrm{cm}^{-3} \mathrm{e}\right.$ taxa de permeabilidade ao $\mathrm{O}_{2} / \mathrm{CO}_{2}=8.250 / 35.569 \mathrm{~cm}^{-3} \mathrm{~m}^{-2}$. $\left.\mathrm{dia}^{-1}\right)$; $\mathrm{T} 3-$ 40 frutos em embalagens de PEBD de $0,022 \mathrm{~mm}+$ adsorvedor de etileno; T4 - 12 frutos em embalagens de PEBD de 0,022 mm; T5 - 12 frutos em embalagens de PEBD de 0,022 mm + adsorvedor de etileno; T6 - 12 frutos em embalagens de PEBD de $0,033 \mathrm{~mm}\left(\mathrm{~d}=0,988 \mathrm{~g} . \mathrm{cm}^{-}\right.$ ${ }^{3} \mathrm{e}$ taxa de permeabilidade ao $\left.\mathrm{O}_{2} / \mathrm{CO}_{2}=4.013 / 21.440 \mathrm{~cm}^{-3} \mathrm{~m}^{-2} \cdot \mathrm{dia}^{-1}\right) \mathrm{e}$ $\mathrm{T} 7$ - 12 frutos em embalagens de PEBD de $0,033 \mathrm{~mm}+$ adsorvedor de etileno. $\mathrm{O}$ acondicionamento dos frutos foi realizado em câmara fria a $0 \pm 0,5^{\circ} \mathrm{C}$ e UR de $95 \pm 3 \%$. As avaliações foram realizadas 24 horas após a colheita, aos 90 dias de AR (12 horas a pós a retirada dos frutos do AR) e aos 90 dias de $\mathrm{AR}+5$ dias de temperatura de 22 $\pm 3{ }^{\circ} \mathrm{C}$ e UR de $75 \pm 5 \%$, simulando o processo de comercialização. As análises realizadas foram as seguintes: ocorrência de degenerescência da polpa, avaliada através da porcentagem de frutos, por tratamento, com a presença de manchas em mais de $25 \%$ da polpa; ocorrência de escurecimento epidérmico, avaliada através da porcentagem de frutos, por tratamento, com a presença do sintoma em mais de $25 \%$ da epiderme; produção e concentração de etileno e $\mathrm{CO}_{2}$ foram quantificadas em cromatógrafo Shimadzù $\mathrm{CR}$ 950, equipado com sistema de detecção por condutividade térmica, resultados expressos em $\mathrm{nL}$ de $\mathrm{CO}_{2} \cdot \mathrm{g}^{-1} \cdot \mathrm{h}^{-1} \mathrm{e} \mathrm{kPa}$, respectivamente. Utilizaram-se como padrões, soluções de etileno e $\mathrm{CO}_{2}$ a 100 ppm e $5 \%$, respectivamente, para cada um dos gases. Para a determinação da produção de etileno e $\mathrm{CO}_{2}, 1 \mathrm{~kg}$ de frutos (de 4 a 6 frutos) foram acondicionados em recipientes herméticos com capacidade unitária de $5 \mathrm{~L}$, durante uma hora a $22^{\circ} \mathrm{C}$. Passado esse período, coletaramse, com auxílio de duas seringas hipodérmicas, $5 \mathrm{ml}$ da atmosfera gasosa de cada recipiente (tratamentos) para dosagem de etileno e $\mathrm{CO}_{2}$. Para a determinação da concentração destes gases, foram coletadas amostras de $5 \mathrm{~mL}$ da atmosfera gasosa de cada embalagem, aos 90 dias de AR, através de seringas hipodérmicas.

Para a confecção da safra de 2001-2002, os melhores tratamentos foram reformatados, utilizando-se somente de embalagens de $0,022 \mathrm{~mm}$ e número inferior a 40 frutos por embalagem. Novamente os tratamentos da safra de 2001-2002 foram submetidos à ação do adsorvedor de etileno. A colheita dos caquis da cv. Fuyu, da SAFRA de 2001-2002, foi realizada no estádio de fisiologicamente maturos, quando os frutos se apresentavam com coloração amareloalaranjada, teor médio de sólidos solúveis totais de $14,6{ }^{\circ}$ Brix, firmeza de polpa média de $82,13 \mathrm{~N}$ e peso médio de $280 \mathrm{~g}$. As embalagens contendo 12 frutos apresentavam dimensões de $0,40 \times 0,42 \mathrm{~m}$, enquanto as embalagens com capacidade para 18 frutos apresentavam dimensões de 0,61 x $0,42 \mathrm{~m}$. Todos os tratamentos preliminares e posteriores à instalação do experimento seguiram os procedimentos da safra de 2000-2001. Os tratamentos estudados foram: T1 - frutos a granel em caixas com capacidade unitária de 20 $\mathrm{kg}$ (controle); T2 - 12 frutos em embalagem de PEBD de $0,022 \mathrm{~mm}$ (d $=0,932 \mathrm{~g} . \mathrm{cm}^{-3} \mathrm{e}$ taxa de permeabilidade ao $\mathrm{O}_{2} / \mathrm{CO}_{2}=8.250 / 35.569 \mathrm{~cm}^{-}$ ${ }^{3} \mathrm{~m}^{-2} \cdot \mathrm{dia}^{-1}$ ); T3 - 12 frutos em embalagem de PEBD de 0,022 $\mathrm{mm}+$ adsorvedor de etileno; T4 - 18 frutos em embalagem de PEBD de 0,022 mm; T5 - 18 frutos em embalagem de PEBD de 0,022 mm + adsorvedor de etileno; T6 - 24 frutos em embalagem de PEBD de 0,022 mm, e T7 - 24 frutos em embalagem de PEBD de 0,022 mm + adsorvedor de etileno. As variáveis avaliadas foram as mesmas da safra de 2000-2001.

$\mathrm{O}$ delineamento experimental empregado, para ambas as safras, foi o inteiramente casualizado, com esquema fatorial $2 \times 4 \times 3$ (presença ou não do adsorvedor de etileno $x$ tipos de acondicionamento $\mathrm{x}$ períodos de análise), com 7 tratamentos e 3 repetições. Os dados foram submetidos à análise de variância e a comparação de médias, pelo teste de Tukey (Pe”0,05).

\section{RESULTADOS E DISCUSSÃO}

A espessura do filme de PEBD e o número de frutos por embalagem afetaram significativamente a ocorrência de distúrbios fisiológicos nos caquis da cv. Fuyu, na safra de 2000-2001 (Tabela 1). Os caquis embalados em PEBD de $22 \mu \mathrm{m}$, contendo doze frutos, independentemente da utilização ou não do adsorvedor, apresentavam-se, ao final de 90 dias de AR, sem a incidência de degenerescência de polpa bem como de escurecimento epidérmico. Analisando esses frutos cinco dias após a saída da câmara fria, o efeito positivo da associação entre a espessura do filme de PEBD $(22 \mu \mathrm{m})$ e o número de frutos por embalagem (doze frutos) foi ainda mais pronunciado em relação aos demais tratamentos. Estes dados são concordantes com os de Ben-Arie \& Zutkhi (1992) e Ferri (2000), em que a escolha adequada do filme de PEBD e do número de frutos por embalagem, à semelhança do que ocorre em sistemas com atmosfera controlada (AC), reduzem as reações oxidativas e diminui os danos por baixas temperaturas. Já nos frutos armazenados a granel e nos frutos acondicionados nas embalagens de $0,022 \mathrm{~mm}$, contendo 40 frutos, também independentemente da presença do adsorvedor, detectou-se alta ocorrência de escurecimento epidérmico, atingindo, aos 90 dias de AR, porcentagens médias de 87,54 e $70 \%$ dos frutos, respectivamente. Após cinco dias de simulação de comercialização, o escurecimento epidérmico foi ainda mais evidente, atingindo quase a totalidade destes frutos, inviabilizando, portanto, como citado por Perez et al. (1995) e Prusky et al. (2001), a sua comercialização em mercados mais exigentes. Já em relação à degenerescência de polpa, 69\% dos frutos armazenados a granel apresentavam o sintoma na saída da câmara, sendo que, após o período de simulação de comercialização, $100 \%$ dos frutos apresentavam esse distúrbio. Da mesma forma, aos 90 dias de AR, os frutos embalados em filmes de PEBD de 0,022 mm, contendo 40 frutos, sem e com o sistema de adsorção de etileno, apresentavam em média $12 \%$ dos frutos com o sintoma de degenerescência da polpa. Avaliando esses frutos após o período de comercialização simulada, pôde-se detectar a evolução desta sintomatologia para até $27 \%$ dos frutos presentes nestas embalagens, denotando-se, assim, a ineficiência desses tratamentos. No entanto, vale ressaltar que, após análises microbiológicas não publicadas e realizadas em ambas as safras, condicionou-se unicamente a natureza dos danos acima descritos a processos fisiológicos, ocasionados, possivelmente, pela exposição dos frutos à temperatura $\mathrm{AR}$ e, sobretudo, pela composição gasosa inadequada no interior das embalagens.

Foram detectados, ainda, escurecimento epidérmico na ordem de $20 \%$, e degenerescência de polpa na ordem de $8,33 \%$, após o período de comercialização simulada, nos frutos das embalagens de 0,033 mm com o adsorvedor. Baseando-se nestes resultados, explicase então a diminuição das desordens fisiológicas da epiderme e 
polpa dos frutos, pelo uso de embalagens de PEBD corretamente projetadas (espessura do filme X número de frutos por embalagem), proporcionando, assim, a diminuição da concentração de $\mathrm{O}_{2}$ e/ou aumento da concentração de $\mathrm{CO}_{2}$, a níveis aceitáveis dentro das embalagens, diminuindo por sua vez a atividade das enzimas fenólicas oxidativas, que podem conduzir ao desenvolvimento de pigmentos de coloração escura.

$\mathrm{Na}$ safra de 2001-2002, os frutos acondicionados em embalagens com capacidade para doze e dezoito frutos, sem a interferência do adsorvedor de etileno, apresentaram-se, em todo o período experimental, sem a ocorrência de distúrbios fisiológicos. Esses resultados demonstram a eficiência da AM no controle de distúrbios fisiológicos em pós-colheita nos caquis Fuyu.

Quanto ao escurecimento epidérmico, aos 90 dias de AR, os frutos armazenados a granel apresentaram $92 \%$ dos frutos com a manifestação deste sintoma, ao passo que, na simulação de comercialização, ampliaram-se as diferenças entre os tratamentos, onde além dos frutos armazenados a granel com 100\% dos frutos com o sintoma, os frutos armazenados em embalagens com capacidade para 24 frutos, independentemente da ação do adsorvedor, apresentaram respectivamente $59 \%$ e $17 \%$ dos frutos com escurecimento epidérmico, inviabilizando, portanto, sua comercialização, principalmente para mercados mais exigentes, como anteriormente citado. Semelhantemente, a degenerescência de polpa também foi detectada nos frutos armazenados a granel e nos frutos armazenados em embalagens com capacidade para 24 frutos. Aos 90 dias de AR, $82 \%$ dos frutos-controle apresentavam este distúrbio. Após os cinco dias de simulação de comercialização, $100 \%$ dos frutos-controle e $83 \%$ e $66 \%$ dos frutos acondicionados nas embalagens para 24 frutos, sem e com o sistema de adsorção, respectivamente, apresentavam o sintoma de degenerescência de polpa.

A concentração de $\mathrm{CO}_{2}$ dentro das embalagens (Figura 1) e a produção de $\mathrm{CO}_{2}$ pelos frutos (Tabela 2) da safra de 2000-2001, foram diretamente influenciadas pela espessura do filme de PEBD, bem como pelo número de frutos por embalagem e o uso do adsorvedor de etileno.

A utilização do sistema de adsorção de etileno interagiu positivamente na redução da concentração de $\mathrm{CO}_{2}$ no interior das embalagens (Figura 1). Enquanto, nas embalagens de 0,022 mm, contendo doze frutos, sem o adsorvedor, observou-se concentrações médias de $\mathrm{CO}_{2}$ na ordem de $10,9 \mathrm{kPa}$, nas mesmas embalagens, com o diferencial do adsorvedor de etileno, e as concentrações médias de $\mathrm{CO}_{2}$ caíram, em média, para 8,05 kPa. Este valor é muito próximo ao recomendado por Brackmann \& Saquet (1995), para o armazenamento de caqui Fuyu em AC, ou seja, uma concentração de $8 \mathrm{kPa}$ de $\mathrm{CO}_{2}$. Nessa situação, e semelhantemente aos resultados observados no presente trabalho, os autores supracitados observaram que os caquis Fuyu mantiveram excelente manutenção dos valores de firmeza de polpa e baixos percentuais de podridões, em três meses de AR.

O aumento do número de frutos por embalagem de doze para 40 e variação da espessura do filme de PEBD de $0,022 \mathrm{~mm}$ para 0,033 $\mathrm{mm}$, nos tratamentos com o adsorvedor de etileno, contribuíram para o aumento excessivo dos níveis de $\mathrm{CO}_{2}$ dentro das embalagens, atingindo valores médios de até $16 \mathrm{kPa}$. Isto resultou em frutos com maiores porcentagens de escurecimento epidérmico, de degenerescência de polpa (Tabela 1) e de odor desagradável. Vidrih et al. (1994) e Ben-Arie \& Zutkhi (1992) citam que o aumento anormal da concentração de $\mathrm{CO}_{2}$ na atmosfera de armazenamento pode desencadear o processo de anaerobiose, resultando na fermentação dos frutos, acumulando etanol e acetaldeído, responsáveis direto pela formação de sabores e odores não característicos aos frutos.

A produção de $\mathrm{CO}_{2}$ (Tabela 2 ) nos caquis Fuyu foi igualmente influenciada pelo uso do adsorvedor de etileno. Assim, todos os frutos mantidos sob o sistema de adsorção apresentaram, aos 90 dias de AR, níveis mais elevados quando comparados aos demais tratamentos, com valores entre 8,7 a $10,5 \mathrm{~nL}$ de $\mathrm{CO}_{2} \cdot \mathrm{g}^{-1} \cdot \mathrm{h}^{-1}$, denotando-se, deste modo, um padrão respiratório constante.

Após o período de cinco dias fora do AR, os frutos acondicionados nas embalagens de $0,022 \mathrm{~mm}$, com capacidade para 40 frutos, e de $0,033 \mathrm{~mm}$ com capacidade para doze frutos, ambos sob o sistema de adsorção de etileno, já não apresentavam padrão respiratório adequado, aparentando estar, pelas baixas produções de $\mathrm{CO}_{2}$ detectadas, em estádio avançado de amadurecimento. Deste modo, esses frutos poderiam ser considerados inaptos para o consumo, devido à elevada porcentagem de frutos apresentando as fisiopatias anteriormente citadas, ou até mesmo com baixíssimo potencial de conservabilidade em pós-colheita. Entretanto, os frutos acondicionados nas embalagens com doze frutos, com o adsorvedor de etileno, apresentavam níveis médios de $8,3 \mathrm{~nL}$ de $\mathrm{CO}_{2} \cdot \mathrm{g}^{-1} \cdot \mathrm{h}^{-1}$, demonstrando assim, intensa atividade respiratória, presumindo-se por sua vez, estarem em estádio menos avançado de amadurecimento. Esta afirmativa é feita com base no estudo da curvapadrão de respiração, onde frutos climatéricos apresentam baixa produção de $\mathrm{CO}_{2}$ inicial na fase pré-climatérica, seguida de um incremento na atividade respiratória, até a máxima produção de $\mathrm{CO}_{2}$ no pico climatérico, sendo que, a partir daí, a produção decresce, caracterizando o pós-climatérico, devido, principalmente, a menor atividade metabólica, característica típica do início da senescência e morte dos frutos.

Sendo assim, na safra 2000-2001, o sachê de adsorção de etileno mostrou-se eficiente na manutenção da produção de $\mathrm{CO}_{2}$ nos frutos e da concentração de $\mathrm{CO}_{2}$ nas embalagens plásticas. No entanto, a simbiose tecnológica do sistema de adsorção de etileno frente aos atributos qualitativos, somente foi verificada nos tratamentos onde se precisava a correta associação entre a densidade do filme de PEBD e o número de frutos por embalagem.

O mesmo ocorrido na safra de 2001-2002, onde a variação do número de frutos por embalagem, bem como a utilização do sistema de adsorção de etileno também influenciaram na concentração de $\mathrm{CO}_{2}$ das embalagens (Figura 2) e na produção de $\mathrm{CO}_{2}$ (Tabela 2) dos caquis Fuyu. Aos 90 dias de AR, os frutos submetidos ao sistema de adsorção de etileno apresentaram as menores concentrações de $\mathrm{CO}_{2}$, dentro de cada tipo de embalagem (Figura 2), indicando, portanto, a eficácia desse sistema na desaceleração da atividade respiratória dos frutos (Mosca et al., 1999). No entanto, a diferença de concentração de $\mathrm{CO}_{2}$ encontrada entre os tratamentos com a utilização do adsorvedor, segundo os próprios autores, foi condicionada à variação do número de frutos por embalagem. Deste modo, o aumento do número de frutos por embalagens proporcionou

FIGURA 1 - Concentração de $\mathrm{CO}_{2}$ em caquis da cv. Fuyu, safra 20002001, armazenados sob refrigeração a $0 \pm 0,5^{\circ} \mathrm{C}$ e 95 $\pm 3 \%$ de UR, durante 90 dias mais 5 dias de condições de comercialização simulada a $22 \pm 3^{\circ} \mathrm{C}$ e $75 \pm 5 \%$ de UR, Farroupilha - RS.

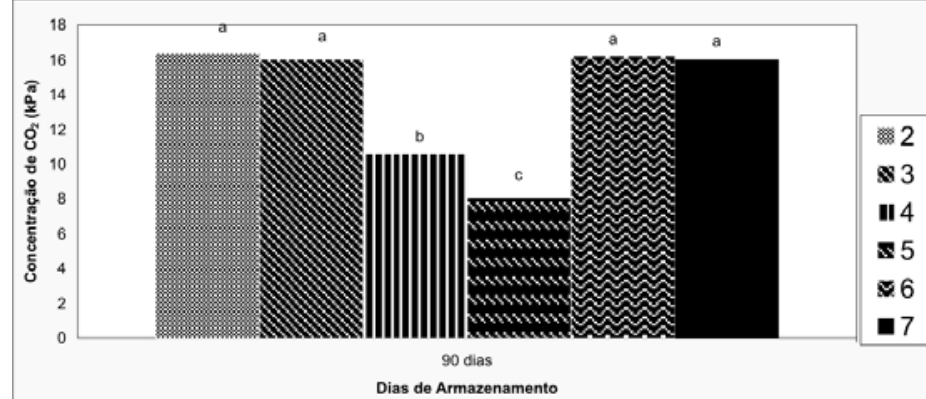

Médias seguidas da mesma letra, nas colunas, não diferem entre si, significativamente, ao nível de $5 \%$ de probabilidade, pelo teste de Tukey. T1: granel; T2: $0,022 \mathrm{~mm} / 12$ fr.; T3: $0,022 \mathrm{~mm} / 12$ fr. + ads; T4: $0,022 \mathrm{~mm} /$ 18 fr.; T5: $0,022 \mathrm{~mm} / 18$ fr. + ads; T6: $0,022 \mathrm{~mm} / 24$ fr.; T7: $0,022 \mathrm{~mm} / 24 \mathrm{fr}$. + ads 
relativo aumento na concentração de $\mathrm{CO}_{2}$

Comportamento similar foi detectado para a produção de $\mathrm{CO}_{2}$ (Tabela 2), onde os frutos acondicionados com o sistema de adsorção de etileno apresentaram melhor preservação da integridade biológica aos 90 dias de AR, principalmente no que concerne a manifestações de fisiopatias (Tabela 1). Neste sentido, os frutos acondicionados em embalagens com capacidade para doze, dezoito e 24 frutos, com o adsorvedor de etileno, apresentaram, respectivamente, 6,$85 ; 5,59$ e $11,89 \mathrm{~nL}$ de $\mathrm{CO}_{2} \cdot \mathrm{g}^{-1} \cdot \mathrm{h}^{-1}$. Após os cinco dias de comercialização simulada, os frutos das embalagens para dezoito e 24 frutos apresentaram, respectivamente, 4,88 e $3,50 \mathrm{~nL}$ de $\mathrm{CO}_{2} \cdot \mathrm{g}^{-1} \cdot \mathrm{h}^{-1}$, demonstrando propensa diminuição da intensidade respiratória, quando comparada aos valores obtidos na saída da câmara fria, característica essa típica de frutos em avançado estádio de

TABELA 1 - Degenerescência de polpa e Escurecimento epidérmico, em porcentagem (\%),em caquis da cultivar Fuyu, safras $2000-2001$ e 2001-2002, frigoarmazenados por 90 dias a $0 \pm 0,5^{\circ} \mathrm{C}$ e umidade relativa de $95 \pm 5 \%$ mais 5 dias a $22 \pm 3{ }^{\circ} \mathrm{C}$ e umidade relativa de $75 \pm 5 \%$, Farroupilha/RS.

\begin{tabular}{|c|c|c|c|c|c|c|c|c|c|c|c|}
\hline & safras & tempo & & & & & atan & & & & \\
\hline Variáveis & & & T1 & T2 & T3 & T4 & T5 & T6 & T7 & D.M.S. & C.V.(\%) \\
\hline \multirow{7}{*}{$\begin{array}{c}\text { Deg. de } \\
\text { Polpa (\%) }\end{array}$} & \multirow{3}{*}{$\begin{array}{c}2000 / 2001 \\
*\end{array}$} & 1 & 0 & 0 & 0 & 0 & 0 & 0 & 0 & 0 & 0 \\
\hline & & 90 & $68,33 \mathrm{a}$ & $11,67 \mathrm{~b}$ & $11,67 \mathrm{~b}$ & $0 \mathrm{c}$ & $0 \mathrm{c}$ & $0 \mathrm{c}$ & $0 \mathrm{c}$ & 9,12 & 25 \\
\hline & & $90+5$ & 100 & $26,67 \mathrm{~b}$ & $23,33 b$ & $0 \mathrm{~d}$ & $0 \mathrm{~d}$ & $0 \mathrm{~d}$ & $8,33 \mathrm{c}$ & 5,27 & 8,36 \\
\hline & \multirow{4}{*}{$\underset{* *}{2001 / 2002}$} & & T1 & T2 & T3 & T4 & T5 & T6 & T7 & & \\
\hline & & 1 & 0 & 0 & 0 & 0 & 0 & 0 & 0 & 0 & 0 \\
\hline & & 90 & $81,67 \mathrm{a}$ & $0 \mathrm{~b}$ & $0 \mathrm{~b}$ & $0 \mathrm{~b}$ & $0 \mathrm{~b}$ & $0 \mathrm{~b}$ & $0 \mathrm{~b}$ & 3,04 & 9,35 \\
\hline & & $90+5$ & $100 \mathrm{a}$ & $0 \mathrm{c}$ & $0 \mathrm{c}$ & $0 \mathrm{c}$ & $0 \mathrm{c}$ & $83,33 \mathrm{ab}$ & $66,67 \mathrm{~b}$ & 21,52 & 21,60 \\
\hline \multirow{8}{*}{$\begin{array}{c}\text { Esc. } \\
\text { Epidêmico } \\
(\%)\end{array}$} & & & T1 & T2 & T3 & T4 & T5 & T6 & T7 & & \\
\hline & & 1 & 0 & 0 & 0 & 0 & 0 & 0 & 0 & 0 & 0 \\
\hline & $2000 / 2001$ & 90 & $86.67 \mathrm{a}$ & $53,33 b$ & $70 \mathrm{ab}$ & $0 \mathrm{c}$ & $0 \mathrm{c}$ & $0 \mathrm{c}$ & $0 \mathrm{c}$ & 17,21 & 20,57 \\
\hline & & $90+5$ & $100 \mathrm{a}$ & $91,67 \mathrm{a}$ & $95 \mathrm{a}$ & $0 \mathrm{c}$ & $0 \mathrm{c}$ & $0 \mathrm{c}$ & $20 \mathrm{~b}$ & 19,95 & 16,33 \\
\hline & \multirow{4}{*}{$2001 / 2002$} & & T1 & T2 & T3 & $\mathrm{T4}$ & T5 & T6 & T7 & & \\
\hline & & 1 & 0 & 0 & 0 & 0 & 0 & 0 & 0 & 0 & 0 \\
\hline & & 90 & $91,67 \mathrm{a}$ & $0 \mathrm{~b}$ & $0 \mathrm{~b}$ & $0 \mathrm{~b}$ & $0 \mathrm{~b}$ & $0 \mathrm{~b}$ & $0 \mathrm{~b}$ & 15,21 & 41,66 \\
\hline & & $90+5$ & $100 \mathrm{a}$ & $0 \mathrm{c}$ & $0 \mathrm{c}$ & $0 c$ & $0 \mathrm{c}$ & $58,33 b$ & $16,67 \mathrm{c}$ & 21,52 & 30,86 \\
\hline
\end{tabular}

As médias seguidas das mesmas letras, nas linhas, não diferem entre si, ao nível de $5 \%$ de probabilidade, pelo teste de Tukey.

D.M.S. - diferença mínima significativa ao nível de 0,05

C.V. - Coeficiente de variação

* - T1: granel; T2: 0,022 mm/40 fr.; T3: 0,022 mm/40 fr. + ads; T4: 0,022 mm/12 fr.; T5: 0,022 mm/12 fr. + ads; T6: 0,033 mm/12 fr.; T7: 0,033 mm/12 fr. + ads.

** - T1: granel; T2: 0,022 mm/12 fr.; T3: 0,022 mm/12 fr. + ads; T4: 0,022 mm/18 fr.; T5: 0,022 mm/18 fr. + ads; T6: 0,022 mm/24 fr.; T7: 0,022 mm/24 fr. $+\operatorname{ads}$.

TABELA 2 - Produção de $\mathrm{CO}_{2}$ e etileno, em nL de $\mathrm{CO}_{2} \cdot \mathrm{g}^{-1} \cdot \mathrm{h}^{-1}$ e $\mathrm{nL}$ de etileno.g $\mathrm{g}^{-1} \cdot \mathrm{h}^{-1}$, respectivamente, em caquis da cultivar Fuyu, safras 2000 2001 e 2001-2002, frigoarmazenados por 90 dias a $0 \pm 0,5{ }^{\circ} \mathrm{C}$ e umidade relativa de $95 \pm 5 \%$ mais 5 dias a $22 \pm 3{ }^{\circ} \mathrm{C}$ e umidade relativa de $75 \pm 5 \%$, Farroupilha/RS.

\begin{tabular}{|c|c|c|c|c|c|c|c|c|c|c|c|}
\hline & safras & tempo & & & & & tratame & & & & \\
\hline Variáveis & & & T1 & T2 & T3 & T4 & T5 & T6 & T7 & D.M.S. & C.V. $(\%)$ \\
\hline \multirow{7}{*}{$\begin{array}{c}\text { Produção } \\
\text { de } \\
\mathrm{CO}_{2} \\
(\mathrm{~nL} \text { de } \\
\left.\mathrm{CO}_{2} \cdot \mathrm{g}^{-1} \cdot \mathbf{h}^{-1}\right)\end{array}$} & \multirow{3}{*}{$2000 / 2001$} & 1 & 2,83 & 2,83 & 2,83 & 2,83 & 2,83 & 2,83 & 2,83 & 0,2746 & 3,48 \\
\hline & & 90 & $3,07 \mathrm{ef}$ & $2,93 \mathrm{f}$ & $9,78 b$ & $4,55 \mathrm{~d}$ & $8,71 \mathrm{c}$ & $3,43 \mathrm{e}$ & $10,44 \mathrm{a}$ & 0,4636 & 2,91 \\
\hline & & $90+5$ & $1,19 \mathrm{c}$ & $1,48 \mathrm{c}$ & $2,77 \mathrm{~b}$ & $2,35 \mathrm{~b}$ & $8,28 \mathrm{a}$ & $2,88 \mathrm{~b}$ & $3,22 \mathrm{~b}$ & 0,7801 & 4,64 \\
\hline & \multirow{4}{*}{$2001 / 2002$} & & T1 & T2 & $\mathbf{T 3}$ & T4 & T5 & T6 & $\mathbf{T} 7$ & & \\
\hline & & 1 & 2,84 & 2,84 & 2,84 & 2,84 & 2,84 & 2,84 & 2,84 & 0,1829 & 2,31 \\
\hline & & 90 & $3,18 \mathrm{e}$ & $4,50 \mathrm{~d}$ & $6,85 b$ & $3,91 \mathrm{de}$ & $5,59 \mathrm{c}$ & $5,38 \mathrm{c}$ & $11,83 \mathrm{a}$ & 0,8564 & 5,21 \\
\hline & & $90+5$ & $1,23 \mathrm{~d}$ & $3,91 \mathrm{c}$ & $7,07 \mathrm{a}$ & $3,62 \mathrm{c}$ & $4,88 \mathrm{~b}$ & $1,44 \mathrm{~d}$ & $3,50 \mathrm{c}$ & 0,3035 & 1,97 \\
\hline \multirow{8}{*}{$\begin{array}{c}\text { Produção } \\
\text { de } \\
\text { Etileno } \\
(\mathbf{n L ~ d e} \\
\text { Etileno } \\
\left.\cdot \mathbf{g}^{-1} \cdot \mathbf{h}^{-1}\right)\end{array}$} & \multirow{4}{*}{$2000 / 2001$} & & T1 & T2 & T3 & T4 & T5 & T6 & T7 & & \\
\hline & & 1 & 1,39 & 1,39 & 1,39 & 1,39 & 1,39 & 1,39 & 1,39 & 0,852 & 2,19 \\
\hline & & 90 & $10,44 \mathrm{a}$ & $9,51 \mathrm{~b}$ & $0,51 \mathrm{e}$ & $5,06 \mathrm{~d}$ & $0,157 \mathrm{f}$ & $7,54 \mathrm{c}$ & $0,35 \mathrm{ef}$ & 0,3507 & 2,62 \\
\hline & & $90+5$ & $19,41 \mathrm{a}$ & $17,64 \mathrm{~b}$ & $0,69 \mathrm{e}$ & $9,91 \mathrm{~d}$ & $0,26 \mathrm{e}$ & $15,50 \mathrm{c}$ & $0,58 \mathrm{e}$ & 0,5511 & 2,16 \\
\hline & \multirow{4}{*}{$2001 / 2002$} & & T1 & T2 & T3 & $T 4$ & T5 & T6 & T7 & & \\
\hline & & 1 & 1,50 & 1,50 & 1,50 & 1,50 & 1,50 & 1,50 & 1,50 & 0,1536 & 3,66 \\
\hline & & 90 & $10,05 \mathrm{a}$ & $4,89 \mathrm{~d}$ & $0,16 \mathrm{e}$ & $5,75 \mathrm{c}$ & $0,23 \mathrm{e}$ & $7,89 \mathrm{~b}$ & $0,35 \mathrm{e}$ & 0,3573 & 3,06 \\
\hline & & $90+5$ & $18,30 \mathrm{a}$ & $7,99 \mathrm{c}$ & $0,58 \mathrm{~d}$ & $8,72 \mathrm{c}$ & $0,93 \mathrm{~d}$ & $15,89 \mathrm{~b}$ & $0,96 \mathrm{~d}$ & 0,8432 & 3,97 \\
\hline
\end{tabular}

As médias seguidas das mesmas letras, nas linhas, não diferem entre si, ao nível de $5 \%$ de probabilidade, pelo teste de Tukey.

D.M.S. - diferença mínima significativa ao nível de 0,05

C.V. - Coeficiente de variação

* - T1: granel; T2: 0,022 mm/40 fr.; T3: 0,022 mm/40 fr. + ads; T4: 0,022 mm/12 fr.; T5: 0,022 mm/12 fr. + ads; T6: 0,033 mm/12 fr.; T7: 0,033 mm/12 fr. + ads.

** - T1: granel; T2: 0,022 mm/12 fr.; T3: 0,022 mm/12 fr. + ads; T4: 0,022 mm/18 fr.; T5: 0,022 mm/18 fr. + ads; T6: 0,022 mm/24 fr.; T7: 0,022 mm/24 fr. + ads. 
FIGURA 2 - Concentração de $\mathrm{CO}_{2}$ em caquis da cv. Fuyu, safra 20012002, armazenados sob refrigeração a $0 \pm 0,5^{\circ} \mathrm{C}$ e 95 $\pm 3 \%$ de UR, durante 90 dias mais 5 dias de condições de comercialização simulada a $22 \pm 3{ }^{\circ} \mathrm{C}$ e $75 \pm 5 \%$ de UR, Farroupilha-RS.

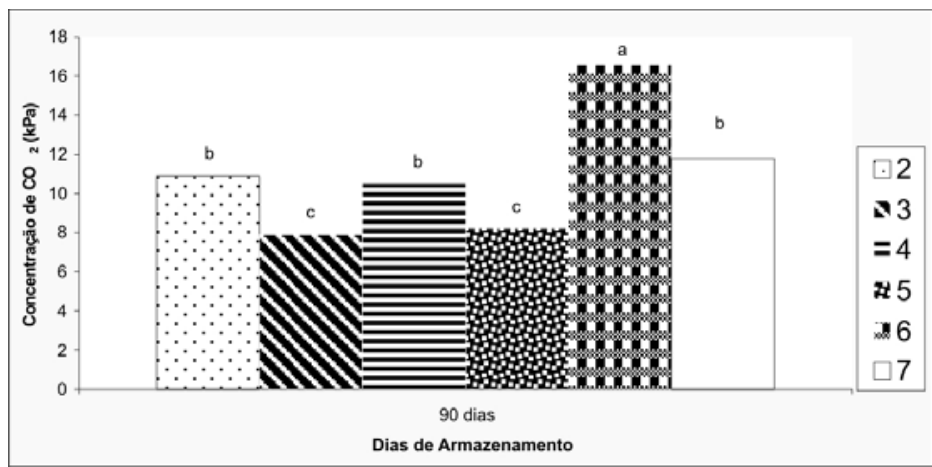

Médias seguidas da mesma letra, nas colunas, não diferem entre si, significativamente, ao nível de $5 \%$ de probabilidade, pelo teste de Tukey T1: granel; T2: $0,022 \mathrm{~mm} / 12 \mathrm{fr}$.; T3: $0,022 \mathrm{~mm} / 12 \mathrm{fr}$. + ads; T4: $0,022 \mathrm{~mm} /$ 18 fr.; T5: 0,022 mm/18 fr. + ads; T6: 0,022 mm/24 fr.; T7: 0,022 mm/24 fr. + ads.

amadurecimento. Já nos frutos acondicionados nas embalagens contendo doze frutos, a produção de $\mathrm{CO}_{2}$ subiu para 7,07 $\mathrm{nL}$ de $\mathrm{CO}_{2} \cdot \mathrm{g}^{-1} \cdot \mathrm{h}^{-1}$, pressupondo-se, pela intensa atividade respiratória desses frutos, um estádio menos avançado de amadurecimento.

Quanto à concentração de etileno nas embalagens, na safra de 2000-2001 (Figura 3), observou-se que, nos tratamentos onde se armazenaram os caquis $F u y u$ na presença do adsorvedor, a concentração de etileno manteve-se menor do que nas embalagens sem o sistema de adsorção, demonstrando, assim, sua eficiência na adsorção de etileno. Porém, nas embalagens de $0,033 \mathrm{~mm}$, contendo doze frutos e $0,022 \mathrm{~mm}$, contendo 40 frutos, apresentavam-se sem condições de consumo, devido à presença de escurecimento epidérmico, degenerescência de polpa e sabores e odores não característicos, ocasionados pela associação inadequada entre a densidade do filme e o número de frutos por embalagem.

Quanto à produção de etileno na safra de 2000-2001 (Tabela 2 ), os resultados seguiram o mesmo comportamento. Os frutos embalados com o adsorvedor de etileno apresentaram valores bem inferiores em relação aos frutos não expostos ao adsorvedor de etileno. Portanto, como os caquis são altamente sensíveis à ação do etileno, a redução da sua concentração nas embalagens, excetuandose para os frutos das embalagens de $0,033 \mathrm{~mm}$ e as embalagens de $0,022 \mathrm{~mm}$ com 40 frutos, proporcionou benefícios tecnológicos, principalmente na prevenção de distúrbios fisiológicos. Em trabalho semelhante realizado com melões da cv. Vedrantais (Ayub et al., 1996), verificou-se que a redução da produção e ação do etileno prolongou a conservação dos frutos, prevenindo a ocorrência de podridões e de distúrbios fisiológicos, especialmente ocasionados pelo uso de baixas temperaturas.

A utilização do sistema de adsorção de etileno, na safra de 2001-2002, também contribuiu para a diminuição da concentração de etileno dentro das embalagens (Figura 4), bem como para a diminuição da produção de etileno nos frutos (Tabela 2). Da mesma forma, além da contenção dos níveis de etileno, a utilização do sachê adsorvedor corroborou frente a melhor manutenção dos atributos de qualidade, onde os frutos acondicionados em embalagens com capacidade para doze e dezoito frutos, com o adsorvedor, apresentaram-se ao final do período experimental isentos de distúrbios fisiológicos. Já os frutos acondicionados nas embalagens para 24 frutos com o adsorvedor de etileno, provavelmente devido à alta concentração de $\mathrm{CO}_{2}$ nas embalagens, proporcionada pelo número elevado de frutos, apresentaram altos índices de escurecimento epidérmico e degenerescência de polpa. Aos 90 dias de AR, a concentração de etileno das embalagens com o sistema de
FIGURA 3 - Concentração de etileno em caquis da cv. Fuyu, safra 2000-2001, armazenados sob refrigeração a $0 \pm 0,5^{\circ} \mathrm{Ce}$ $95 \pm 3 \%$ de UR, durante 90 dias mais 5 dias de condições de comercialização simulada a $22 \pm 3{ }^{\circ} \mathrm{C}$ e $75 \pm 5 \%$ de UR, Farroupilha - RS

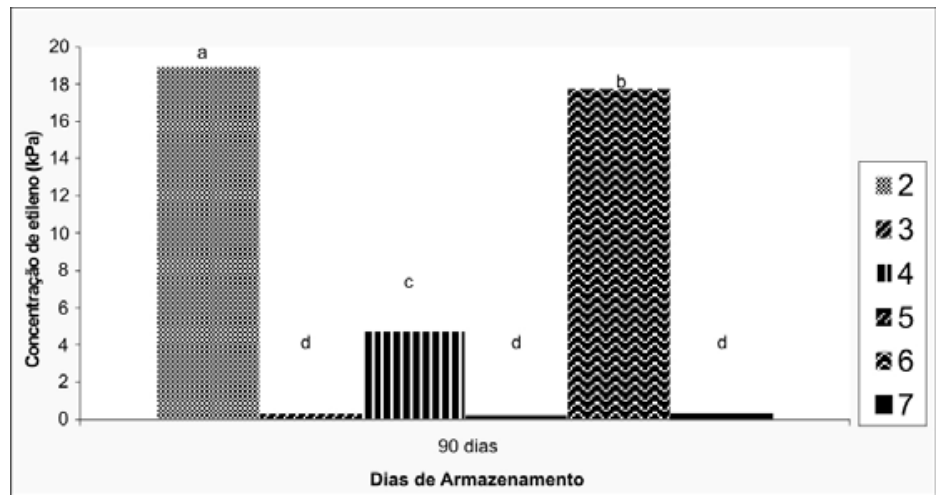

Médias seguidas da mesma letra, nas colunas, não diferem entre si, significativamente, ao nível de $5 \%$ de probabilidade, pelo teste de Tukey. T1: granel; T2: 0,022 mm/12 fr.; T3: 0,022 mm/12 fr. + ads; T4: $0,022 \mathrm{~mm} /$ 18 fr.; T5: 0,022 mm/18 fr. + ads; T6: 0,022 mm/24 fr.; T7: 0,022 mm/24 fr. + ads.

FIGURA 4 - Concentração de etileno em caquis da cv. Fuyu, safra 2001-2002, armazenados sob refrigeração a $0 \pm 0,5^{\circ} \mathrm{C}$ e $95 \pm 3 \%$ de UR, durante 90 dias mais 5 dias de condições de comercialização simulada a $22 \pm 3^{\circ} \mathrm{Ce}$ $75 \pm 5 \%$ de UR, Farroupilha - RS.

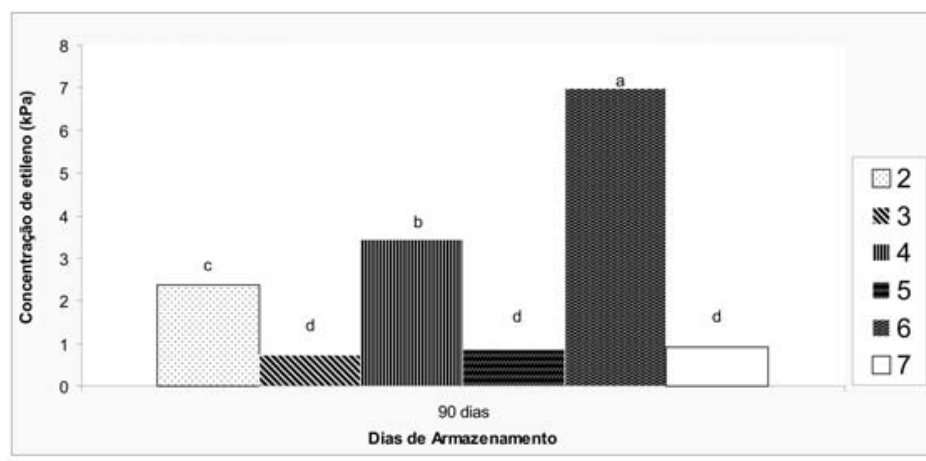

Médias seguidas da mesma letra, nas colunas, não diferem entre si, significativamente, ao nível de $5 \%$ de probabilidade, pelo teste de Tukey. T1: granel; T2: $0,022 \mathrm{~mm} / 12$ fr.; T3: $0,022 \mathrm{~mm} / 12 \mathrm{fr}$ + ads; T4: $0,022 \mathrm{~mm} /$ 18 fr.; T5: 0,022 mm/18 fr. + ads; T6: 0,022 mm/24 fr.; T7: 0,022 mm/24 fr. + ads.

adsorção estava entre 0,73 e $0,91 \mathrm{kPa}$, enquanto nas embalagens sem o adsorvedor, as concentrações variavam entre 2,86 e $6,89 \mathrm{kPa}$.

A produção de etileno na saída do AR, para os tratamentos com o sachê adsorvedor, variava entre 0,16 e $0,35 \mathrm{~nL}$ de etileno.kg${ }^{1} \cdot \mathrm{h}^{-1}$, enquanto nos tratamentos sem o sistema de adsorção, as concentrações de etileno variavam entre 4,89 e 10,05 nL de etileno.kg${ }^{1} \cdot \mathrm{h}^{-1}$. Após a saída da câmara fria, observou-se o mesmo comportamento, onde para os tratamentos com o sistema de adsorção foram constatados níveis de 0,58 a $0,96 \mathrm{~nL}$ de etileno.kg${ }^{1} \cdot \mathrm{h}^{-1}$, enquanto nos tratamentos sem o sistema de adsorção, as concentrações sofreram incremento para até $18,29 \mathrm{~nL}$ de etileno. $\mathrm{kg}^{-}$ ${ }^{1} \cdot \mathrm{h}^{-1}$. Estes dados indicam que os frutos frigoarmazenados sem a presença do sistema de adsorção apresentavam metabolismo mais acelerado do que os frutos frigoarmazenados com o sachê adsorvedor etileno.

\section{CONCLUSÕES}

É possível concluir que o adsorvedor de etileno influi diretamente na produção e concentração de $\mathrm{CO}_{2}$ /etileno em caquis Fuyu, não refletindo, necessariamente, na diminuição da ocorrência dos distúrbios fisiológicos. Nesse caso, deve-se levar em 
consideração o número de frutos por embalagem e a espessura do filme de PEBD utilizado. A embalagem de PEBD de 0,022 mm de espessura, contendo doze ou dezoito frutos, independentemente de um sistema de adsorção de etileno, promove a adequada manutenção da qualidade sensorial do caqui Fuyu, durante 90 dias de AR.

\section{REFERÊNCIAS}

AYUB, R.; GUIS, M.; BEN-AMOR, M.; GILLOT, L.; ROUSTAN, J.P.; LATCHÉ, A.; BOUZAYEN, M.; PEACH, J.C. Expression of ACC oxidade antisense gene inhibits ripening of cantaloupe melon fruits. Nature Biotechnology, New York, n.14, p. 862-866, 1996.

BEN-ARIE, R.; ZUTKHI, Y. Extending the storage life of "Fuyu" persimmon by modified-atmosphere packaging. HortScience, Alexandria v.27, n.7, p.811 -813, 1992.

BEN-ARIE, R. Commercial quality of "Fuyu" persimmon. Postharvest Biology and Technology, Amsterdan, v.14, n.3, p.311-317, 1995.

BRACKMANN, A.; SAQUET, A.A. Efeito da temperatura e condições de atmosfera controlada sobre a conservação de caqui. Ciência Rural, Santa Maria, v.25, n.3, p.375-378, 1995.

CEAGESP. Boletim anual. São Paulo: Secretaria de Agricultura e Abastecimento. 1997.

CHAVES, A L.; ZIMMER, P. D.; SILVA, J. A; ROMBALDI, C. V. Caracterização Imunoquímica da ACC oxidase em frutas climatéricas. Ciência e Tecnologia de Alimentos, Campinas, $\mathrm{n}$. 17, p. 320-324, 1997.
FERRI, V.C. Controle da maturação e conservação de caquis (Diospyrus kaki, L.) cultivar Fuyu. Pelotas. 2000. 103f. Tese (Doutorado em agronomia)- Faculdade de Agronomia Eliseu Maciel, Universidade Federal de Pelotas, Pelotas, 2000.

MAcRAE, E.A. Development at chilling injury in New Zealand grown Fuyu' persimmon during storage. New Zealand Journal of Experimental Agriculture, Auckland, n.15, p.333-344, 1987.

MOSCA, J. L.; MUGNOL, M. M.; VIEITES, R. L. Atmosfera modificada na pós-colheita de frutas e hortaliças. Botucatu: FEPAF, 1999, 28p.

PEREZ, A.; BEN-ARIE, R.; DINOOR, A.; GENIZI, A.; PRUSKY, D. Prevention of black spot disease in persimmon fruit by gibberellic acid and iprodione treatments. Phytopatology, St. Paul, n. 85, p.221-225. 1995.

PRUSKY, D.; ESHEL, D.; KOBILER, I.; YAKOBY, N.; BENOMOUALEM, D.; ACKERMAN, M.; ZUTHJI,Y; BEN-ARIE, R. Postharvest chlorine treatments for the control of the persimmon black spot disease caused by Alternaria alternata. Postharvest Biology and Technology, Amsterdan, n.22, p.271-297. 2001

VIDRIH,R.; SIMSIC, M; HRIBAR, J.; PLESTENJAK, A. Adstringency removal by high $\mathrm{CO}_{2}$ treatment in persimmon fruit (Diospyrus kaki L.). Acta Horticulturae, Wageningen, n.368, p.652-656, 1994. 